\title{
Rainfall estimation for real time flood monitoring using geostationary meteorological satellite data
}

Watcharee Veerakachen*, Mongkol Raksapatcharawong

Faculty of Engineering, Kasetsart University, 50 Ngamwongwan Rd., Bangkok 10900 Thailand. fengwrv@ku.ac.th

ABSTRACT: Rainfall estimation by geostationary meteorological satellite data provides good spatial and temporal resolutions. This is advantageous for real time flood monitoring and warning systems. However, a rainfall estimation algorithm developed in one region needs to be adjusted for another climatic region. This work proposes computationally-efficient rainfall estimation algorithms based on an Infrared threshold rainfall (ITR) method calibrated with regional ground truth. Hourly rain gauge data collected from 70 stations around the Chao-Phraya river basin were used for calibration and validation of the algorithms. The algorithm inputs were derived from FY-2E satellite observations consisting of infrared and water vapour imagery. The results were compared with the Global Satellite Mapping of Precipitation (GSMaP) near real time product (GSMaP_NRT) using the probability of detection (POD), root mean square error (RMSE) and linear correlation coefficient (CC) as performance indices. Comparison with the GSMaP_NRT product for real time monitoring purpose shows that hourly rain estimates from the proposed algorithm with the error adjustment technique (ITR_EA) offers higher POD and approximately the same RMSE and CC with less data latency.

KEYWORDS: hourly rain rate, infrared threshold rainfall, satellite remote sensing

\section{INTRODUCTION}

The estimation of rainfall is an important and contributing factor to several issues regarding the impact of climate change. Natural disasters such as floods, landslides and droughts are the result of excesses or deficits of rainfall in many parts of the world. Enhancing our capability to monitor rainfall with high spatial and temporal resolutions can be advantageous in preventing and mitigating the severity of flood calamities in the future ( $\mathrm{Li}$ et al., 2013). There are several methods for rainfall measurement and estimation. Rain gauges can directly measure the amount of rainfall, while radars play an important role 
in real time rainfall monitoring although its accuracy decreases with distance. However, in some areas, both rain gauge and radar are not feasible due to cost, technological infrastructure or topography. Rainfall estimation by satellites is therefore an alternative to achieve real time rainfall estimation with high spatial resolution and wide coverage. Despite surface rainfall gauge measurements being point based over an integral of time, while satellite estimates are instantaneous measurements over an integral of space, relationships between the satellite and surface datasets have been found in previous works (Goodman et al., 1994). Since point gauge rainfall measurements are considered representative of the average rainfall hourly accumulated over co-located satellite pixel areas, these data are used to correlate with satellite data received at the beginning of each hour to compute hourly rain estimates over each pixel area. The computed rain estimates are considered as representatives of the averages hourly rainfall measured by point gauges.

A number of rainfall estimation products with near-global coverage have the potential to be used. For hourly monitoring purposes, most products use input data from the thermal infrared (TIR) sensors onboard geostationary (GEO) satellites that may be combined with passive microwave (PM) data to increase its accuracy. Some of these well-known techniques include the Precipitation Estimation from Remote Sensing Information using Artificial Neural Network (PERSIANN; Hsu et al., 1997), the Climate Prediction Center MORPHing technique (CMORPH; Joyce et al., 2004), and the Global Satellite Mapping of Precipitation (GSMaP; Ushio et al., 2009). The main differences among them are the manner in which data inputs are combined. The PERSIANN algorithm uses a three-layer feed-forward artificial neural network (ANN) technique to estimate rainfall rate from TIR data. The CMORPH technique, one of the best products at present, combines the greater accuracy of PM rainfall estimates with the better temporal resolution of TIR observations. The PM rainfall estimates are morphed by motion vectors derived from half-hourly TIR data. The GSMaP algorithm is similar to CMORPH in which the PM estimates are propagated using TIR-derived motion vectors. A difference is that GSMaP algorithm applies the Kalman filter to the propagated PM estimates to update TIR rainfall estimates when the PM estimates are absent. There are two available GSMaP products: the near real time version GSMaP_NRT and the non-real time version GSMaP_MVK which provides more accuracy by using backward propagation and additional data from the Advanced Microwave Sounding Unit (AMSU). A comparison of the performance of both GSMaP products is shown in our previous work (Veerakachen et al, 2014). In this work, only GSMaP_NRT product is considered since GSMaP_MVK product is not available for real time monitoring purpose.

The accuracy of these estimates may vary over different regions of the world. Evaluation of satellite precipitation products by using a station network of about 600 rain gauges over Colombia, Dinku 
et al. (2009) found CMORPH to be the best product, whereas the PERSIANN product overestimated and GSMaP_NRT underestimated the rainfall. For real time monitoring, the PERSIANN rain estimate is available with 2 days latency (http://hydis8.eng.uci.edu/persiann), the CMORPH product is available with 18 hours delay (http://www.cpc.ncep.noaa.gov/products/janowiak/cmorph description.html), while the GSMaP_NRT algorithm offers estimates with 4 hours data latency (http://sharaku.eorc.jaxa.jp/GSMaP/index.htm). Since the least data latency is preferred for flood monitoring and warning systems, GSMaP_NRT is the most appropriate rain estimate product available at present.

To reduce the time delay for real time flood monitoring, an alternative for satellite rainfall estimation is to develop GEO-IR rain estimate technique using only TIR input data obtained from GEO meteorological satellites. This data can be received (sub-) hourly through a satellite-based Digital Video Broadcast via Satellite (DVB-S) service under the Integrated Global Data Dissemination Service (IGDDS) project of the World Meteorological Organization (WMO). Data latency could therefore be reduced enabling real time rainfall estimation. There are a number of GEO-IR based rainfall estimation technique. For flash flood monitoring a technique with less complexity and less data input is preferred. The well-known Convective Stratiform Technique (CST) is complicated and related to the climatic conditions (Adler and Negri, 1988) while the NESDIS Auto Estimator considers several factors in addition to IR cloud top temperature, such as cloud growth rate, relative humidity, and cloud structure (Vicente et al., 1998). The simple GOES Precipitation Index (GPI) estimates rain within the area of 50*50 $\mathrm{km}$ by the fraction of area that has cloud top temperature less than 235K (Arkin and Meisner, 1987). In the Tropics, the optimal threshold for cold cloud filtering has been found to be $253 \mathrm{~K}$ (Goodman et al., 1994). The Negri-Adler-Wetzel (NAW) technique also uses $253 \mathrm{~K}$ threshold to identify cloud area (Negri et al., 1984). However, the NAW technique gives only two rain estimates, $8 \mathrm{~mm} \cdot \mathrm{h}^{-1}$ for heavy rain and 2 $\mathrm{mm} . \mathrm{h}^{-1}$ for light rain. The Infrared Power law Rain rate (IPR) relationship between rainfall amount and IR brightness temperature, representing cloud top temperature, was found to be useful in estimating rain rate as a continuous function of cloud brightness temperature (Goodman et al., 1994). The Infrared Threshold Rainfall (ITR) technique has been proposed using $253 \mathrm{~K}$ threshold to identify rain cloud and IPR relationship for rainfall estimation (Pegram et al., 2004). The accuracy of rain estimates may be improved through the use of regional rainfall statistics.

The purpose of this work is to develop rainfall estimation algorithms based on an ITR method adjusted by local rain gauge data that is (1) computationally efficient using only TIR inputs from GEO satellite to reduce estimation latency providing more lead time for flood monitoring and warning system and (2) sufficiently competent to offer equivalent performance to the GSMaP_NRT by compensating for 
performance degradation through regional data calibration. Results are validated and compared with those of GSMaP_NRT to examine which algorithm would be appropriate for a flood warning and monitoring system.

\section{MATERIALS AND METHODS}

\section{Study Area and Data Sources}

The Chao-Phraya river basin, located between $13.5^{\circ}-16.1^{\circ} \mathrm{N}$ and $99.5^{\circ}-101^{\circ} \mathrm{E}$, is chosen as the study area. With a total area of $20,125 \mathrm{~km}^{2}$, the basin is regarded as a principal water way with the most fertile rice and fruit-growing area of the country; it is also heavily affected by major floods and droughts. Within this area, rain-gauge data from 70 stations (Fig. 1), collected during the rainy season (May to October) in 2009 and 2010, are provided by the Thai Meteorological Department (TMD). These datasets are used to calibrate the GEO-IR rainfall algorithms and compare the results with GSMaP precipitation products over the same period. The GSMaP product used for comparison is the GSMaP_NRT with 4 hours data latency available for downloading from the website. 


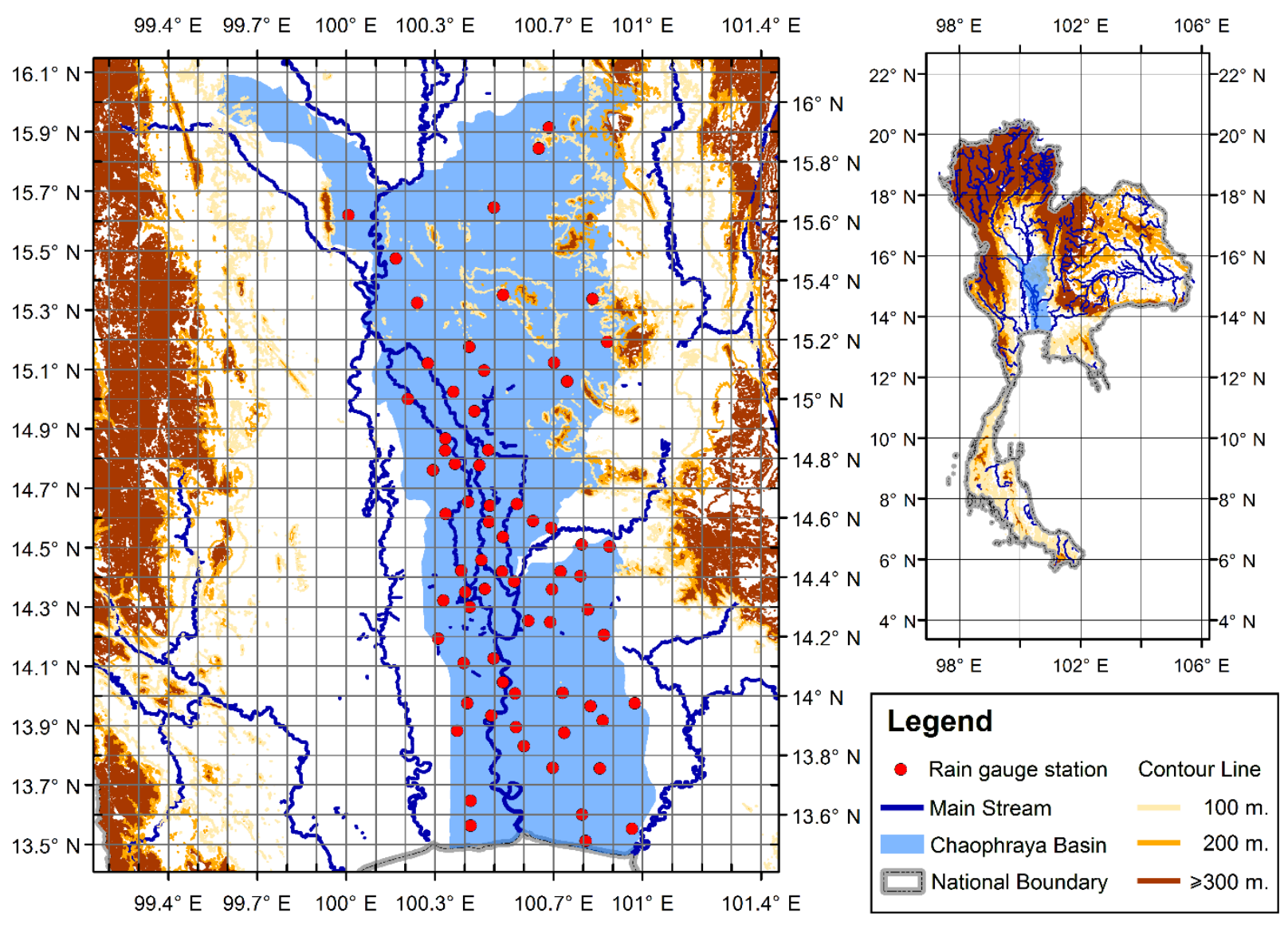

Fig. 1 Thailand meteorological department rain gauge network consisting of 70 stations around the Chao-Phraya River Basin.

The TIR input of GEO-IR rain estimate algorithms is derived from FY-2E satellite data received hourly at Chulabhorn Satellite Receiving Station through a DVB-S system. The Visible and Infrared Spin Scan Radiometer (VISSR) of FY-2E satellite, located at $105^{\circ} \mathrm{E}$ longitude covering the region of Thailand, is equipped of a 5 channel-sensor on board (Hu et al., 2013). The brightness temperature of IR1 channel, 10.3-11.3 $\mu \mathrm{m}$, is chosen as the input of proposed algorithms. The IR1 brightness temperature represents cloud top temperatures that are related to rainfall occurrence and rain rate. Numerical data is extracted from the VISSR files and converted to brightness temperatures using the information given in the files' document sector. The GEO-IR rainfall algorithms are developed through the relationship between the brightness temperatures and the rainfall measurements to indicate the occurrence of rainfall and corresponding rain rate. The IR3 brightness temperature at $6.5 \mu \mathrm{m}$, representing water vapor in the atmosphere, is also used to adjust the rain rate in error adjustment algorithms. A database was setup for hourly data sets with co-located data from the TMD rain gauges, IR1 and IR3 temperature from FY-2E satellite, and GSMaP_NRT rain estimate. 


\section{ITR based rainfall estimation algorithms}

Although the ITR method has limitations in the underestimation of severe convective rainfall due to the IPR relationship and also the underestimation of warm coastal and orographic rain due to $253 \mathrm{~K}$ threshold, the algorithm is simple and requires only the IR brightness temperature as input. Therefore the ITR technique was adopted in this study, with some modifications carried out to overcome the limitation mentioned above.

\section{Probabilistic matching technique}

The IPR relationship derived from a statistical non-linear regression of co-located surface rain gauges and IR1 temperatures shows that rain rate and IR1 are inversely related i.e., rain rate increases as IR1 decreases. However, the IPR relationship tends to underestimate severe rainfall particularly associated with very low cloud top temperature. The variance of rainfall amount increases as cloud top temperature decreases because not all high clouds produce heavy rain. The probability of high cloud resulting in heavy rain is quite rare, although most heavy rain is caused by high cloud. To increase the accuracy in estimating severe rainfall — an important triggering factor of flash floods, probabilistic matching is applied to re-distributed pairs of IR brightness temperature (IR1) and measured rainfall amount. Each $(\mathrm{x}, \mathrm{y})$ pair of IR1 and rain rate measured by total hourly rainfall were matched such that the probability that IR 1 is less than $x$ equals the probability that rain rate is more than $y$. Therefore, the probability matching provides higher rain estimates at very low brightness temperatures that relate to severe storms.

\section{Threshold adjustment technique}

Another disadvantage of the ITR method is underestimation of rain caused by warm cloud (IR1 $>253 \mathrm{~K})$. Therefore a threshold adjustment was attempted to increase the probability of warm rain detection. Increasing the threshold can increase the detection probability of warm rain, however, this also increases the probability of false alarms i.e., the technique detects rain when there is actually no rain. Conversely, the probability of missed rain, i.e. the algorithm detects no rain when rainfall actually occurs, would increase if the threshold decreases. Therefore, based on the statistics of regional rainfall, a new threshold is specified by the brightness temperature at which the probability of misses equals to the probability of false alarms, called Adjusted ITR (AITR). This approach resulted in a new threshold at $262 \mathrm{~K}$ for the study area around the Chao- 
Phraya River Basin. The same technique can be applied for other regions which may result in a different threshold depending on the corresponding regional rainfall statistics.

\section{Error Adjustment method}

The simple ITR method suffers from inherent limitations of a single-channel IR-based technique. It assumes that the rain rate is a function of cloud top temperature (IR1) without considering different dynamic processes occurring inside the clouds. Therefore, the algorithm is developed using additional data from the water vapour channel. The difference between the cloud top temperature (IR1) and the water vapour temperature (IR3) is defined as the Brightness Temperature Difference (BTD). The MultiSpectral Rain Rate technique uses BTD to identify cirrus — high cloud that produces no rain. Statistical analysis showed that IR3 and BTD are highly correlated with rain rate. This work proposes a method to improve ITR rain estimate by using IR3 and BTD to estimate corresponding errors of the ITR technique, an error estimator is added to the ITR method. This process computes error as a function of IR3 and BTD (Fig. 2). The corresponding error is deducted from the ITR estimate to adjust the rain rate produced by the ITR technique. If the error causes the adjusted rain estimate to be negative, the adjustment will lead to no rain detection which results in a slight decrease in the probability of detection (Fig. 3).

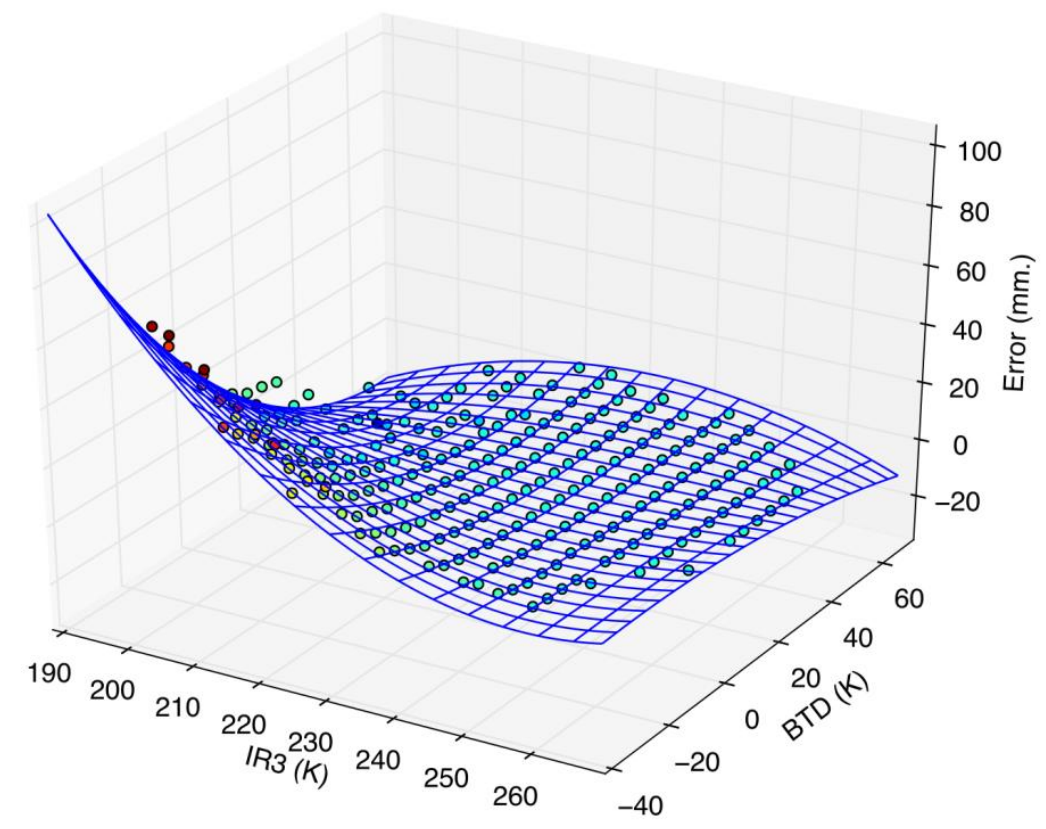

Fig. 2 Error estimator is a function of IR3 and BTD. Points shown are errors between rain gauge measurements and ITR/AITR outputs corresponding to IR3 and BTD for each dataset. 


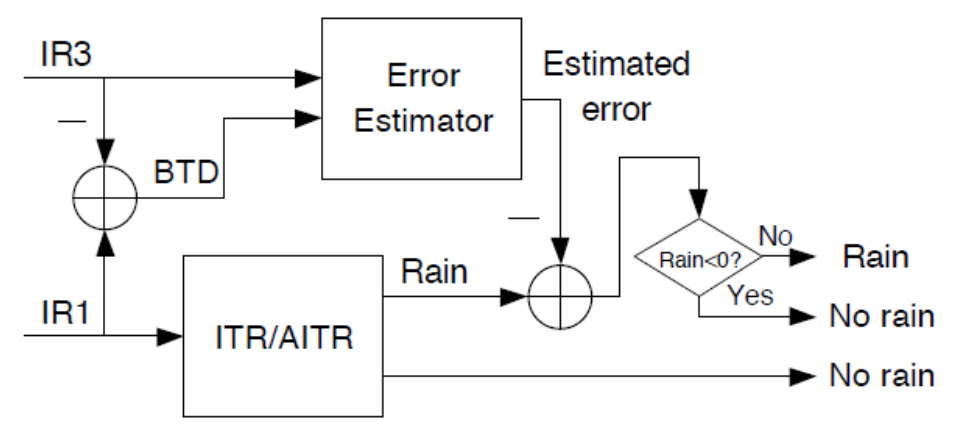

Fig. 3 Conceptual block diagram of error adjustment technique augmenting the ITR-based rainfall estimation algorithm.

Validation with rain gauge data

Applying probability matching, threshold adjustment, and error adjustment technique to ITRbased rainfall estimation algorithm, four modified algorithms are proposed (Table 1). These algorithms output were validated and compared with the GSMaP_NRT product using hourly rain gauge measurement. Although the rain gauge data is a point measurement while the satellite estimate is a spatial average, the rain estimate at the co-located pixel of the gauge station is used for validation. Note that the spatial resolution of GSMaP_NRT product is $10 * 10 \mathrm{~km}$ per pixel while the GEO-IR rain estimate has better spatial resolution at $5 * 5 \mathrm{~km}$ per pixel.

Table 1 Summary of the proposed ITR-based GEO-IR rainfall estimation algorithms

\begin{tabular}{llll}
\hline $\begin{array}{l}\text { Algorithm } \\
\text { name }\end{array}$ & $\begin{array}{l}\text { GEO-IR } \\
\text { input from } \\
\text { FY-2E } \\
\text { satellite }\end{array}$ & $\begin{array}{l}\text { Rain } \\
\text { detection } \\
\text { threshold } \\
(\mathbf{K})\end{array}$ & Modification \\
\hline ITR_PM & IR1 & 253 & Probability matching \\
AITR_PM & IR1,IR3 & 262 & Probability matching, threshold adjusting \\
ITR_EA & IR1 & 253 & Probability matching, error adjusting \\
AITR_EA & IR1,IR3 & 262 & Probability matching, threshold and error adjusting \\
\hline
\end{tabular}

\section{RESULTS AND DISCUSSIONS}

In this study, the performance of rainfall estimation algorithms was evaluated in terms of rainfall detection and estimation capability. Rainfall detection capability was evaluated based on accuracy (ACC), probability of detection (POD), and false-alarm ratio (FAR). These statistics were calculated from the number of occurrences for each scenario in the contingency table (Table 2 and 3 ). 
Table 2 Contingency table used to calculate performance indices for rainfall detection.

\begin{tabular}{llll}
\hline & & \multicolumn{2}{l}{ Observed by rain gauges } \\
& & Rain & No Rain \\
\hline Detected by & Rain & Hit $(a)$ & False alarm $(b)$ \\
\cline { 2 - 4 } satellite rain estimate products & No Rain & Miss $(c)$ & Correct negative $(d)$ \\
\hline
\end{tabular}

Table 3 Description of ACC, POD, and FAR

\begin{tabular}{lcl}
\hline Index & Expression & Implication \\
\hline ACC & $A C C=\frac{a+d}{a+b+c+d}$ & $\begin{array}{l}\text { The fraction of the correct detection to the number of overall } \\
\text { events. }\end{array}$ \\
\hline POD & $P O D=\frac{a}{a+c}$ & $\begin{array}{l}\text { The ratio of correct rain detection to the number of rain } \\
\text { events observed. }\end{array}$ \\
\hline FAR & $F A R=\frac{b}{a+b}$ & $\begin{array}{l}\text { The fraction of rain detection that turn out to be wrong. } \\
\end{array}$
\end{tabular}

In general, there exists a tradeoff between POD and FAR in a rainfall detection algorithm, i.e., methods increase the number of hits in exchange for an increase in the number of false alarms. The results (Table 4) show, by the number of hits and false alarms, that the GSMaP_NRT algorithm is conservative in the detection of rain while both AITR algorithms favor rain due to an increase in the decision threshold. Sorting from the lowest to the highest POD, the order of algorithms are GSMaP_NRT, ITR_EA, AITR_EA, ITR_PM, and AIR_PM, respectively. Since no rain event dominates all scenarios, the algorithms with lower POD and FAR offer higher ACC. Therefore, in view of ACC GSMaP_NRT performs best, and AITR_PM is the worst. The error adjustment method has an effect of reducing POD and FAR. Therefore, the method offers higher ACC than that without error adjustment. However, for monitoring and warning systems, POD is more crucial than ACC. The ITR_PM technique increased by almost twice the POD while its ACC was slightly diminished compared to that of GSMaP_NRT.

Table 4 Hourly validation statistics using rain gauge data around the Chao-Phraya river basin during May to October, 2009 and 2010.

\begin{tabular}{llllll}
\hline Algorithms/Products & GSMaP_NRT & ITR_PM & AITR_PM & ITR_EA & AITR_EA \\
\hline hit_count & 10750 & 18790 & 21485 & 13287 & 15918 \\
false_alarm_count & 46605 & 118270 & 169349 & 87707 & 154803 \\
miss_count & 19327 & 9016 & 6321 & 14519 & 11888 \\
correct neg. count & 459638 & 353270 & 302191 & 383833 & 316737 \\
\hline ACC & 0.8771 & 0.7451 & 0.6482 & 0.7953 & 0.6662 \\
POD & 0.3574 & 0.6758 & 0.7727 & 0.4778 & 0.5725 \\
\hline
\end{tabular}




\begin{tabular}{llllll}
\hline FAR & 0.8126 & 0.8629 & 0.8874 & 0.8684 & 0.9068 \\
RMSE & 1.9140 & 3.1946 & 3.5938 & 1.8764 & 2.1308 \\
CC & 0.0882 & 0.1469 & 0.1497 & 0.0873 & 0.0615 \\
\hline
\end{tabular}

Although, five validation indices were used in this study, POD and RMSE are of most importance for the purpose of real time monitoring and warning systems - false alarm is more acceptable than the miss events. AITR_PM offers the highest POD but is not appropriate since its false alarm is too high to obtain acceptable accuracy $(<70 \%)$. This also applies to the AITR_EA algorithm. The ITR_PM shows a promising way to improve the detection ability over the GSMaP_NRT. Compared with the GSMaP_NRT, the POD of ITR_PM increases from 0.3574 to 0.6758 while the FAR increases approximately by only 0.05 (Table 4), however, the RMSE increases from 1.9140 to 3.1946 as a result of overestimation of high rain rates. The ITR_EA algorithm, with error calibrated by regional rain gauge data, offers an alternative compromise for detection and estimation capacity. Compared with GSMaP_NRT, the performance of ITR_EA algorithm has improved i.e., higher POD and slightly lower RMSE.

Rainfall estimation performance was assessed based on root mean square error (RMSE) and linear correlation coefficient (CC). Compared with GSMaP_NRT, the ITR_EA algorithm offers approximately equivalent performance in RMSE and CC (Table 4). The error adjustment process used in ITR_EA and AITR_EA helps to improve the RMSE at the cost of a decrease in the CC. Without error adjustment, the probability matching method improves the possibility to estimate heavy rain. This technique thus increases the CC but the RMSE is increased due to a large error in the case of false alarms.

Further discussion is about an aspect concerning the validation of hourly rain rate estimated by satellite rainfall estimation algorithms in a practical flood disaster scenario caused by heavy rainfall. In this scenario, although rain occurred for a short period, the rainfall intensity was very high ( $>50 \mathrm{~mm} / \mathrm{hr}$ ) leading to a flood disaster. Hourly rain rate observed by local rain gauge in Ayuthaya and Saraburi — a province affected by flood reported on August $28^{\text {th }}, 2010$ — were compared with rain estimates from GSMaP_NRT product and GEO-IR rainfall estimation algorithms (Fig. 4 and 5). It is shown that ITR_PM and AITR_PM algorithms had the ability to keep track of heavy rainfall more than other algorithms. Therefore, it is noteworthy that ITR_PM algorithm is useful in the monitoring of flash flood incidents. 


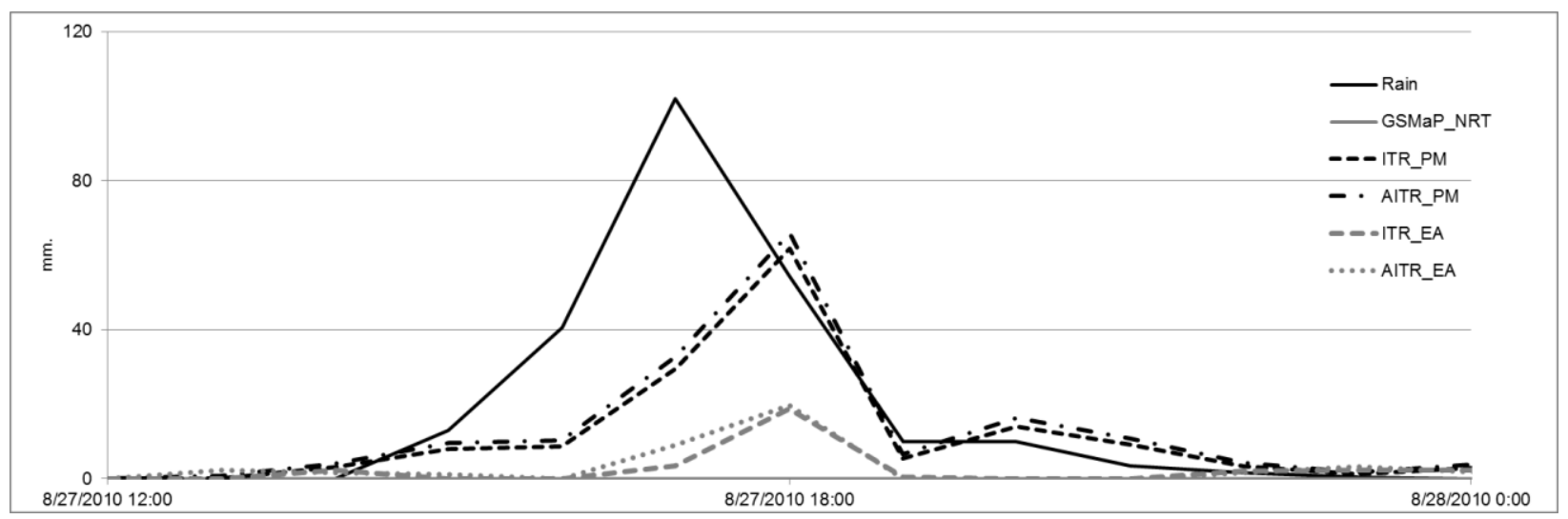

Fig. 4 Hourly rain estimate from each algorithm compared with rain gauge in heavy rainfall scenario measured by TMD station in Ayutthaya on August 27-28, 2010.

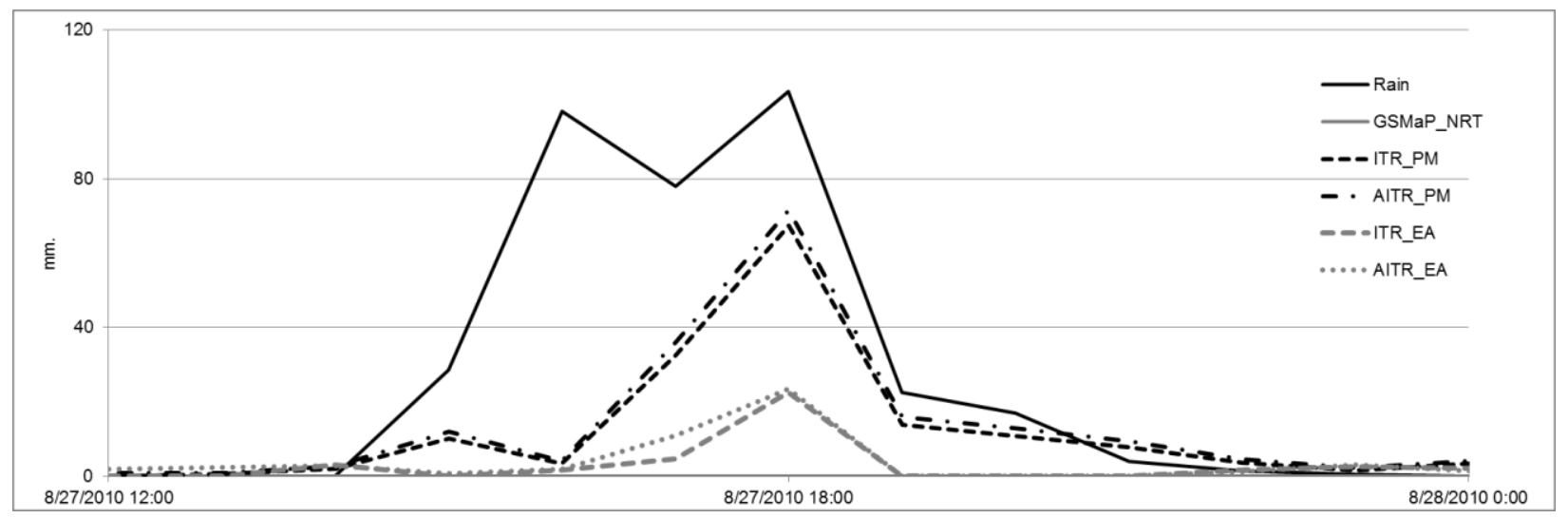

Fig. 5 Hourly rain estimate from each algorithm compared with rain gauge in heavy rainfall scenario measured by TMD station in Saraburi on August 27-28, 2010.

In addition to the use of hourly rain rate for flood monitoring system, daily rainfall accumulating from hourly rainfall can also be used as an input to the flood forecasting algorithm. Monthly averaged daily performance evaluated by POD and RMSE are shown to illustrate effectiveness of each satellite rain estimate product in this aspect (Fig. 6 and 7). Except for GSMaP_NRT, POD of satellite rain estimate product was over 0.8 (Fig. 6) and mostly more than 0.9. The POD of GSMaP_NRT was relatively low at the beginning of the rainy season but the algorithm performed better after the first half. Therefore, evaluated by local rain gauge, the detection capability of GSMaP_NRT varies by rain forming processes that are different over the rainy season. Among the proposed GEO-IR rain estimate algorithms, ITR_EA has lowest RMSE that is comparable to the RMSE of GSMaP_NRT (Fig. 7). This suggests that ITR_EA should be a good candidate for providing daily rain input to a flood forecasting model. 


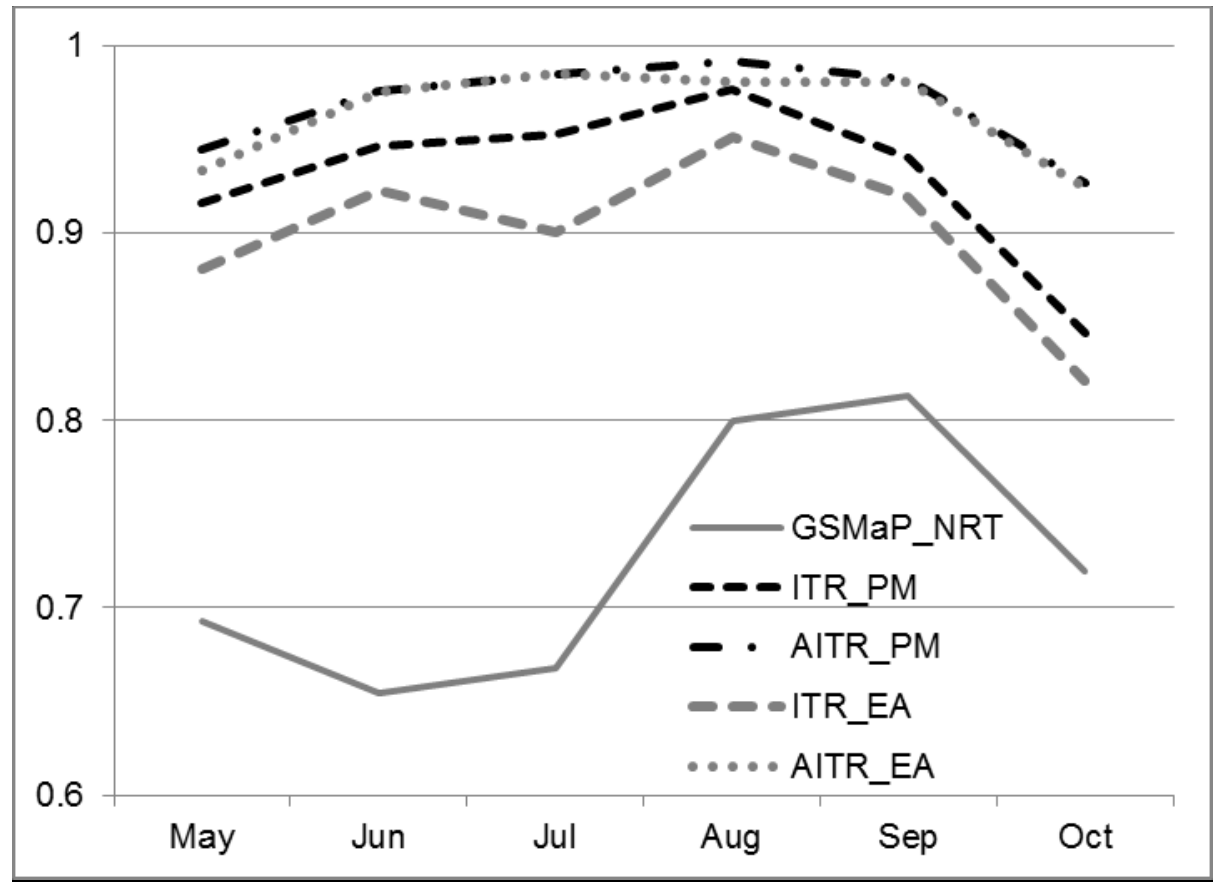

Fig. 6 Daily POD grouped by month during May to October, 2009 and 2010.

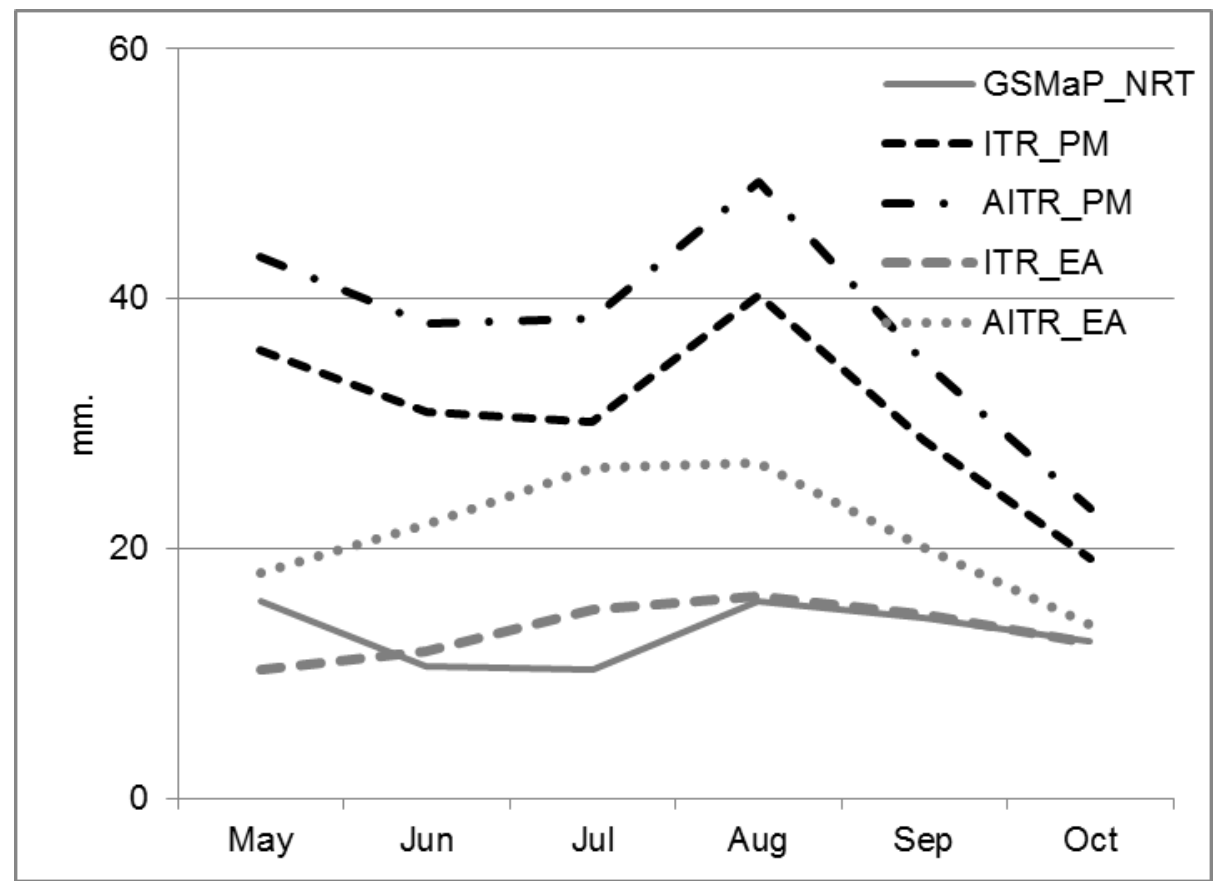

Fig. 7 Daily RMSE grouped by month during May to October, 2009 and 2010.

\section{CONCLUDING REMARKS}


Rainfall estimation algorithms for real time flood monitoring and warning system were developed. The algorithms use GEO-IR satellite data to estimate hourly rain rate with countrywide coverage and high spatial resolution comparing to rain gauge. To attain real time estimates, all algorithms require only GEO-IR satellite data input and are based on the ITR method with a simple detection and estimation technique enabling the algorithm to be computed in real time. Using only GEO-IR satellite data as an input to the ITR_EA algorithm, the result is encouraging in that the real time monitoring approaches and exceeds detection and estimation performance compared with the GSMaP_NRT product that uses combined TIR and PM satellite data with 4 hours delay.

Acknowledgements: This study was supported by the Science and Technology Research Partnership for Sustainable Development (JST-JICA). The authors thank Thailand meteorology department (TMD) for their kind provision of rainfall ground truth data.

\section{REFERENCES}

Adler, RF, and AJ Negri. 1988. "A satellite infrared technique to estimate tropical convective and stratiform rainfall." Journal of Applied Meteorology vol 27 p 30-51.

Arkin, PA and Meisner, BN. 1987. "The relationship between large-scale convective rainfall and cold cloud over the Western Hemisphere during 1982-1984." Monthly Weather Review $115,51-74$.

Dinku, Tufa, Franklyn Fuiz, Stephen J. Conner, and Pietro Ceccato. 2009. "Validation and Intercomparison of Satellite Rainfall Estimates over Colombia." Journal of Applied Meteorology and Climatology 49: 1004-1014.

Geoffrey Pegram, Izak Deyzel, Scott Sinclair, Pieter Visser, Deon Terblanche, and George Green. 1995. "Daily Mapping of 24-Hr Rainfall at Pixel Scale Over South Africa Using Satellite, Radar and Rain-gauge Data." 2nd Workshop of the International Precipitation Working Group.

Goodman, B, WP Menzel, and DW Martin. 1994. "A non-linear algorithm for estimating 3hourly rain rates over Amazonia from GOES/VISSR observations." Remote Sensing Reviews 169-177. 
Hsu, K. L., X. Gao, S. Sorooshian, and H. V. Gupta. 1997. "Precipitation estimation from remotely sensed information using artificial neural networks." J. Appl. Meteor. 36: 11761190.

Hu XQ, Xu N, Weng FZ, Zhang Y, Chen L, Zhang P. 2013. "Long-term moni-2 infrared channel calibration using AIRS and IASI." IEEE Transactions on Geoscience and Remote Sensing 51 (10): 5008-18.

Joyce, R. J., J. E. Janowiak, P. A. Arkin, and P. Xie. 2004. "CMORPH: A method that produces global precipitation estimates from passive microwave and infrared data at high spatial and temporal resolution." J. Hydormeteor 5: 487-503.

Li SG, Zhang Q, Xu CY. 2013. "Assessing the performance of satellite-based precipitation products and its dependence on topography over Poyang Lake basin." Theor Appl. Climatol 115: 713-719.

Negri, A J., R. F. Adler, and P. J. Wetzel. 1984. "Rain estimation from satellite: an examination of the Griffith-Woodley technique." J. Climate Appl. Meteorol. 23: 102-116.

Ushio, Tomoo, Kazushi Sasashige, Takuji Kubota, Shoichi Shige, Ken'ichi Okamoto, Kazumasa Aonashi, Toshiro Inoue, et al. 2009. "A Kalman Filter Approach to the Global Satellite Mapping of Precipitation (GSMaP) from Combined Passive Microwave and Infrared Radiometric Data." Journal of the Meteorological Society of Japan 87A: 137-151.

Veerakachen W, Raksapatcharawong M, Seto S. 2014. "Performance evaluation of Global Satellite Mapping of Precipitation (GSMaP) products over the Chaophraya river basin, Thailand." Hydrological Research Letters 8 (1): 39-44.

Vicente, Gilberto A., Roderick A Scofield, and W. Paul Menzel. 1998. "The operational GOES infra-red Rainfall Estimation Technique." Bulletin of the American Meteorological Society 1883-1998. 


\section{FIGURE LEGENDS}

Fig. 1 Thailand meteorological department rain gauge network consisting of 70 stations around the Chao-Phraya River Basin.

Fig. 2 Error estimator is a function of IR3 and BTD. Points shown are errors between rain gauge measurements and ITR/AITR outputs corresponding to IR3 and BTD for each dataset.

Fig. 3 Conceptual block diagram of error adjustment technique augmenting the ITR-based rainfall estimation algorithm.

Fig. 4 Hourly rain estimate from each algorithm compared with rain gauge in heavy rainfall scenario measured by TMD station in Ayutthaya on August 27-28, 2010.

Fig. 5 Hourly rain estimate from each algorithm compared with rain gauge in heavy rainfall scenario measured by TMD station in Saraburi on August 27-28, 2010.

Fig. 6 Daily POD grouped by month during May to October, 2009 and 2010.

Fig. 7 Daily RMSE grouped by month during May to October, 2009 and 2010. 